\title{
Commentary
}

\section{The role of Yoga in working from home during the COVID-19 global lockdown}

\author{
Kanupriya Sharma ${ }^{\mathrm{a}}$, Akshay Anand ${ }^{\mathrm{a}, *}$ and Raj Kumar ${ }^{\mathrm{b}}$ \\ ${ }^{a}$ Neuroscience Research Lab, Department of Neurology, PGIMER, Chandigarh, India \\ ${ }^{\mathrm{b}}$ Department of English and Cultural Studies, Panjab University, Chandigarh, India
}

Received 5 June 2020

Accepted 8 June 2020

\begin{abstract}
.
BACKGROUND: The COVID-19 pandemic has become a major cause of stress and anxiety worldwide. Due to the global lockdown, work, employment, businesses and the economic climate have been severely affected. It has generated stress among people from all sections of society, especially to workers who have been assigned to cater to healthcare service or those constrained to secure daily essential items. It is widely perceived that elderly or those affected by diabetes, hypertension and other cardiovascular diseases (CVD's) are prone to COVID-19. As per an ongoing survey, the initial data shows that the above-mentioned anxiety and stress cause insomnia, and has the considerable potential to weaken the immune system, the sole protection against the virus.

OBJECTIVE: This study focuses on the need of Yoga practice at work places and at home during the global lockdown due to the COVID-19 pandemic.

METHODS: Literature was searched using PubMed and Google Scholar for COVID-19-related stress and anxiety at work and society due to the worldwide lockdown. The predisposing comorbidities, viral mechanism of action and treatment regimen were also searched. Yoga-based intervention studies and online programs were also searched.

RESULTS: As the lockdown cannot last forever and workplaces will have to be functional soon, there is an increased possibility of recurrent infection. Therefore, Yoga can provide the necessary tool for risk reduction, amelioration of stress and anxiety and strengthening of the immune function. The online platforms provide a good media for Yoga training at work places and homes.

CONCLUSION: Due to social distancing norms, the availability of Yoga trainers has become restricted. Yoga practice is actively sought to achieve reduced anxiety and stress so that improved sleep may positively impact immunity. As a consequence, there is a spurt in social media, catering to daily online Yoga sessions which apparently prove useful in providing accessible means to achieve mental as well as physical well-being.
\end{abstract}

Keywords: Insomnia, anxiety, immunity, mental health, COVID-19, Yoga

\section{Introduction}

*Address for correspondence: Akshay Anand, PhD, Professor, Neuroscience Research Lab Department of Neurology, Post Graduate Institute of Medical Education and Research, Chandigarh, India. Tel.: +91 9914209090; E-mail: akshay1anand@ rediffmail. com.
First detected in the Chinese city Wuhan in late 2019, COVID-19 belongs to the family of SARS and MERS-CoV. The number of infected people and consequent deaths have increased dramatically as a result of rapid viral infections across the globe. The elderly 
and those with underlying medical conditions are at an increased risk of developing COVID-19. Recent reports reveal that coronaviruses, such as SARS and MERS, are capable of modulating the host immune detection [1] and creating underlying medical conditions and weaken immune systems making them more vulnerable to infections [2,3]. Pharmacological and non-pharmacological immune-modulatory interventions, empowered to combat such pathogens, are being discovered through intensified experimentation and trials [4-6].

Since the declaration of the COVID-19 outbreak as a pandemic by the World Health Organization (WHO), the uncertainty, stress and pre-conceived opinions are being circulated in social media, further exacerbating the situation causing fear, anxiety and stress in communities and healthcare workers alike. In order to restrain the transmission of infection (and panic), several 'hotspot localities' have been locked down. These conditions further escalated the conditions of stress among residents of the pandemic and containment regions [7], either due to new situations of working from home or loss of jobs. Healthcare workers with a medical and para-clinical background are also at high risk of developing psychological stress, strain, depression and post-traumatic stress disorder $[8,9]$ and requires rehabilitative therapy to deal with the crisis.

Traditional Indian health practices such as Yoga, Siddha, Ayurveda and homeopathy have been known to prevent, treat and control several diseases [10]. These practices are 5000 years old and have been cited in ancient Indian literature. Yoga is one of the widely accepted and structured lifestyle practices which promotes the integration of the mind, body and soul. These practices are known to have a strong influence on the psychology [11] and immune system [12].

The Common Yoga Protocol was proposed by the Indian government for International Yoga Day. This Protocol includes all the aspects of Yoga practice, for instance postures (Asanas), breathing techniques (Paranayama) and meditation (Dhyana) [13]. Yoga has been shown to exert health promoting effects by influencing the neuro-psycho-immune capacity through the improvement of psychological balance. Therefore, the Common Yoga Protocol can be universally adopted as a recourse to modify the lifestyle of every age group and to provide mental and physical health benefits during the pandemic outbreak. Thus, we advocate the practice of the Common Yoga Protocol for risk reduction of COVID-19, as it may be useful for the enhancement of immunity and to combat anxiety, glucose, hypertension and stress induced by the pandemic.

\section{Fundamental mechanism for COVID-19 infection}

COVID-19 is an associate of Coronaviridae (CoV). It is an enveloped virus with single stranded positive sense Ribo Nucleic Acid (RNA) as a genetic material. COVID-19 infection predominantly causes respiratory illness with asymptomatic or mildly symptomatic fever, cough, fatigue and diarrhea and severe acute respiratory distress syndrome (ARDS) along with fatal multi organ collapse in certain cases [14]. COVID-19 incorporates spike protein which first binds itself to the Angiotensin Converting Enzyme 2 (ACE 2) receptor on the host cell surface. Once the binding has taken place, the $\mathrm{S}$ protein undergoes conformational change in order to facilitate fusion of viral envelope to cell membrane via the endosomal pathway. Next, the virus releases its RNA into the host cell, where viral proteins and genome RNA are subsequently assembled into virions in Endoplasmic Reticulum (ER) and Golgi. Finally, it is transported via vesicles and released from the cell transfecting others simultaneously [15].

\section{Pre-existing health conditions increase the mortality rate of COVID-19 infection}

Coronaviruses have been observed as primary sources of respiratory and intestinal infections which embrace influenza, respiratory syncytial virus and pneumonias-a trigger to cardiovascular diseases (CVDs) [16]. CVD as linked to comorbidities raises the incidence and severity of infectious diseases like COVID-19 [17]. The data that has been provided here proves the aforementioned contention: A study, which reported the mortality due to COVID-19 and cardiac injury, includes 416 hospitalized patients of which 57 died. Among them, $10.6 \%$ of the patients had a coronary heart disease, $4.1 \%$ suffered from heart failure, $5.3 \%$ had cerebrovascular diseases and at least 20\% had cardiac injury [18]. Another study from Wuhan, China reported 187 COVID-19 patients, out of which 43 died. $35 \%$ of the infected patients had cardiovascular diseases (hypertension, coronary heart disease, or cardiomyopathy) (13). Another Chinese study consisted of 44,672 confirmed cases, out of 
which 1023 (2.3\%) died, and out of the total deaths, $10.5 \%$ had underlying cardiovascular diseases with COVID-19 symptoms [19]. Diabetic patients have an equal risk of succumbing to COVID-19 infection, especially in countries like India with high prevalence of diabetic population which predisposes them to high risk of COVID-19 and its related complications [20], posing challenges for costs of healthcare.

Since a lavish lifestyle further increases the risk of diseases like COVID-19 [21], diabetes [22] and hypertension, a cost effective non-pharmacological intervention such as Yoga can effectively reduce the risk of CVDs which consequently increases the risk of COVID-19 and related complications. Yoga can reduce the risk of cardiovascular diseases and COVID-19 by modulating weight [23], lipid profile [24], blood pressure [25] and stress [26].

\section{Anxiety and stress due to the COVID-19 pandemic}

There is a universal anxiety due to the current COVID-19 pandemic. This permeates through all sections of society. Some underprivileged sections of the society, especially migrant workers, are more prone to the present circumstances, because of its profound impact on their 'daily wage' employment composition [27, 28]. On the other hand, there is a section of society which has witnessed increased cases of domestic violence due to the lockdown [29]. Similarly, a shortage of protective gears to take care of COVID-19 patients generates a sense of fear among frontline workers which makes them susceptible to stress and anxiety [30]. As workplaces have been closed and businesses have been affected due to a nationwide lockdown, the general anxiety and stress exerts a significant impact on physiological changes in individuals [31, 32]. These physiological alterations make them more vulnerable to viral infections [33-35]. It is widely accepted that stress, insomnia and anxiety can lead to a decrease in melatonin levels (a natural antioxidant) in the human body [36]. Various studies have demonstrated that the melatonin level decreases with age $[37,38]$. As a result, the elderly appear more prone to the COVID-19 infection. Thus, increased melatonin levels may partially compensate for the age-related risk of COVID-19 infection. Further, it is pertinent to point out that the current lockdown has also adversely affected the daily schedule and sleep cycle [39], thus affecting the circadian rhythm with a bearing on the immune system [40]. This highlights the importance of self -regulatory mind-body interventions such as a structured daily schedule and Yoga practice.

\section{Current therapies for prevention and treatment of the COVID-19 pandemic}

Currently, various vaccines and drugs are in the clinical trial phase for the prevention and treatment of COVID-19. For example, the drugs hydroxychloroquine (HCQ) [41], remdesivir [42], rotonavir-lopinavir [43] and convalescent plasma therapy are undergoing clinical trials. So far none of these drugs have been proclaimed as a final call for the COVID-19 infection. Therefore, high quality multicentric randomized trials with larger sample sizes are required to evaluate the efficacy of prospective drugs. The aforementioned alternative therapies which can enhance the immunity and prevent the infection are imperative. An interdisciplinary task force under the supervision of Health Ministry AYUSH (Ministry of Ayurveda, Yoga and Naturopathy, Unani, Siddha and Homeopathy) and Indian Council of Medical Research is planning to conduct an HCQ versus Ashwagandha clinical trial to understand the comparative effectiveness of prophylaxis in healthcare workers [44]. Since the lockdown eventually has to be relaxed and the workplaces have to be fully operational with social distancing norms, a good immune system based on cost effective non-pharmacological intervention seems to be an attractive choice to combat infection.

\section{Yoga enhances the immune system and psychological development of human beings}

Yoga is widely accepted as a potential regimen in order to address emotional, physical and mental attributes. The example cited above has demonstrated that it relieves the mental stress [45] and enhances immunity to a disease and can also be helpful in the current pandemic [46]. Yoga maintains a balance in the autonomic nervous system through enhancing the parasympathetic activity and lowering the sympathetic activity else it can result in a state of depression and stress. The practice of Yoga also enhances GABA, the inhibitory neurotransmitter system in part via the stimulation of the vagus nerve [47]. The stress hormones (such as cortisol) which 
Table 1

Tabulated Common Yoga Protocol

\begin{tabular}{|c|c|c|c|}
\hline S. no. & Asanas & Protocol & Duration \\
\hline 1. & Prayer & To enhance the benefits of practice. & 2 minutes \\
\hline 2. & Loosening practices & $\begin{array}{l}\text { Increases microcirculation: } \\
\text { - Neck bending } \\
\text { - Trunk movement (Katishaktivikasak) } \\
\text { - Knee movement }\end{array}$ & 5 minutes \\
\hline 3. & Yogasanas (1 minute per Asana) & $\begin{array}{l}\text { Standing postures } \\
\text { - Tadasana (Palm tree pose) } \\
\text { - Vkrsasana (Tree posture) } \\
\text { - Padahastasana (The hands and feet posture) } \\
\text { - Ardhacakrasana (The half wheel posture) } \\
\text { - Trikonasana (The triangle posture) } \\
\text { Sitting postures } \\
\text { - Bhadrasana (The firm auspicious posture) } \\
\text { - Ardhaustrasana (The half camel posture) } \\
\text { - Sasankasana (The hare posture) } \\
\text { - Ardhaustrasana } \\
\text { - Vakrasana (The spinal twist posture) } \\
\text { Prone postures } \\
\text { - Bhujangasana (The cobra posture) } \\
\text { - Salabhasana (The locust posture) } \\
\text { - Makarasana (The crocodile posture) } \\
\text { Supine postures } \\
\text { - Setubandhasana (The bridge posture) } \\
\text { - Uttanapadasna } \\
\text { - Ardhahalasana (Half plough posture) } \\
\text { - Pavanamuktasana (The wind releasing posture) } \\
\text { - Savasana (The dead body posture) }\end{array}$ & 15 minutes \\
\hline 4. & Kapalbhati & Forceful exhalation by contracting the abdominal muscles. & 2 minutes \\
\hline 5. & Pranayama (2 minutes each) & $\begin{array}{l}\text { - Nadishodhana or Anulomvilom (Alternate nostril breathing) } \\
\text { - Satali Pranayama } \\
\text { - Bhramari Pranayama } \\
\text { - Dhyan in Shambavi Mudra }\end{array}$ & 8 minutes \\
\hline 6. & Meditation & For stress-free deep relaxation and silencing of the mind. & 12 minutes \\
\hline 7. & Sankalpa & Commitment to be a healthy, happy, peaceful and joyful human being. & 1 minute \\
\hline 8. & Shanti Path & Prayer for happiness, health and peace for all. & 1 minute \\
\hline
\end{tabular}

compromise the immune system [48, 49], can be balanced through Yoga practice because of its inclusion of slow breathing practice which improves the lung capacity and respiratory health for optimal performance and wellness [50]. In addition, it has been shown that Yoga assists in improving the blood circulation in order to supply the oxygenated blood to multiple organs for smooth optimal function [51].

Recent research on healthcare professionals has shown a significant improvement in personal accomplishment, depression, anxiety, stress, perceived resilience and compassion by practice of Yoga [52]. Research on Yoga techniques has produced some interesting findings about their key role in reducing the levels of inflammatory cytokines. This includes IL-1 $\beta$, IL 6 and TNF $\alpha$ which implicates risk reduction for diseases with inflammatory component [12]. Despite research and development activities in Yoga, it has not been officially accepted as a public health intervention strategy in the workplace.
Since the workplaces and hospitals are replete with continuous anxiety, stress and fear of infection and a restricted access to parks, gyms and swimming, an in-house Yoga practice provides a remedy to an inactive lifestyle and work from home during the current COVID-19 pandemic.

\section{Yoga protocols to cope with the stressful situation}

Various online platforms, for example Yoga Scholars PGIMER on Facebook, are providing uninterrupted live sessions which focus on an interface between public and healthcare workers. These sessions comprise experts from Yoga, science and spiritual fields to promote the philosophy of Yoga practice and to provide demonstrations of Yoga practices, seemingly helpful in anxiety and stress management. These online platforms have been 
endorsed by the Ministry of AYUSH (@Ministry of AYUSH, Government of India).

In this context, it is important to note that Nagarathna et al. have recently proposed an age-specific Yoga protocol which postulates the therapeutic effect of Yoga in COVID-19 prevention and management [53]. They conducted a study using an eight pronged Yoga breathing procedure which consists of very simple neck muscle relaxation movements and Asana with breathing techniques, including adaptation to a chair. There was a significant improvement in the peak expiratory flow rate by $>20 \%$ within 30 minutes of the practice, and the patients developed confidence and reduced panic and anxiety [53].

These modules are available on http://svyasa. edu.in and have been developed with the help of experts in Yoga techniques. A clinical study on these protocols demonstrates interest and recovery among hospitalized COVID-19 patients in various countries, communicated as a separate publication [53].

Some Yoga practices which are a part of the Common Yoga Protocol [13] have been described to successfully decrease stress and anxiety levels, and have presented other benefits as well. These practices include: Anulom Vilom Pranayama (alternate nostril breathing), Bhramhari Pranayama and meditation. Practices like Kapalbhati (forceful exhalation by contracting the abdominal muscles) have been found useful to purify the frontal air sinuses and also aid to overcome cough disorders which maintains the health of respiratory tract and boosts immunity.

Along with the above-mentioned Yoga practices, certain Asanas, if practiced under supervision, have also been shown to relieve stress. This includes Sasankasana (hare posture), Bhujangasana (cobra posture), Makrasana (crocodile posture) and Setubandhasana (bridge posture). Most of these constitute a part of the Common Yoga Protocol practiced on International Yoga Day. The practice of some of these protocols at workplaces/offices can enable risk reduction for COVID-19.

\section{Conclusion}

The COVID-19 pandemic has resulted in a global shutdown with people becoming more vulnerable to new mental, emotional and physical challenges as they have been restricted to work from home. The exacerbation of existing comorbid conditions and further deterioration in mental health can be addressed by work from home-adapted Yoga techniques (e.g. 5 min Y break AYUSH Protocol) by utilization of online portals and novel Yoga modules. 45 minute Common Yoga Protocol practiced on International Day of Yoga is recommended for this. Maintaining health due the unavailability of drugs and vaccines to combat COVID-19 is crucial. Based on the current evidence, Yoga practice can reduce the risks of comorbid conditions and strengthen the immune system by relieving stress and anxiety or directly improving immune markers or both. Yoga can be employed at home and workplaces alike.

\section{Conflict of interest}

None to report.

\section{References}

[1] Vellingiri B, Jayaramayya K, Iyer M, Narayanasamy A, Govindasamy V, Giridharan B, Ganesan S, Venugopal A, Venkatesan D, Ganesan H, Rajagopalan K. COVID-19: A promising cure for the global panic. Science of the Total Environment. 2020:138277.

[2] Guan WJ, Liang WH, Zhao Y, Liang HR, Chen ZS, Li YM, Liu XQ, Chen RC, Tang CL, Wang T, Ou CQ. Comorbidity and its impact on 1590 patients with Covid-19 in China: A Nationwide Analysis. European Respiratory Journal. 2020;55(5).

[3] Toniato E, Ross R, Kritas S. How to reduce the likelihood of coronavirus-19 (CoV-19 or SARS-CoV-2) infection and lung inflammation mediated by IL-1. 2020.

[4] Sanders JM, Monogue ML, Jodlowski TZ, Cutrell JB. Pharmacologic treatments for coronavirus disease 2019 (COVID-19): A review. Jama. 2020;323(18):1824-36.

[5] Jayawardena R, Sooriyaarachchi P, Chourdakis M, Jeewandara $C$, Ranasinghe $P$. Enhancing immunity in viral infections, with special emphasis on COVID-19: A review. Diabetes \& Metabolic Syndrome: Clinical Research \& Reviews. 2020 Apr 16.

[6] Baden LR, Rubin EJ. Covid-19-the search for effective therapy. 2020, Mass Medical Soc.

[7] Zhang Y, Ma ZF. Impact of the COVID-19 pandemic on mental health and quality of life among local residents in Liaoning Province, China: A cross-sectional study. International journal of Environmental Research and Public Health. 2020;17(7):2381.

[8] Tan BY, Chew NW, Lee GK, Jing M, Goh Y, Yeo LL, Zhang K, Chin HK, Ahmad A, Khan FA, Shanmugam GN. Psychological impact of the COVID-19 pandemic on health care workers in Singapore. Annals of Internal Medicine. 2020.

[9] Lai J, Ma S, Wang Y, Cai Z, Hu J, Wei N, Wu J, Du H, Chen T, Li R, Tan H. Factors associated with mental health outcomes among health care workers exposed to coronavirus disease 2019. JAMA network open. 2020;3(3):e203976.

[10] Choudhary A, Pathak A, Manickam P, Purohit M, Rajasekhar TD, Dhoble P, Sharma A, Suliya J, Apsingekar 
D, Patil V, Jaiswal A. Effect of Yoga versus Light Exercise to Improve Well-Being and Promote Healthy Aging among Older Adults in Central India: A Study Protocol for a Randomized Controlled Trial. Geriatrics. 2019;4(4):64.

[11] La Torre G, Raffone A, Peruzzo M, Calabrese L, Cocchiara RA, D'Egidio V, Leggieri PF, Dorelli B, Zaffina S, Mannocci A. Yoga and Mindfulness as a Tool for Influencing Affectivity, Anxiety, Mental Health, and Stress among Healthcare Workers: Results of a Single-Arm Clinical Trial. Journal of Clinical Medicine. 2020;9(4):1037.

[12] Falkenberg R, Eising C, Peters M. Yoga and immune system functioning: A systematic review of randomized controlled trials. Journal of Behavioral Medicine. 2018;41(4):467-482.

[13] Ministry of AYUSH, I., Common Yoga Protocol. 2014.

[14] Zhu H, Rhee JW, Cheng P, Waliany S, Chang A, Witteles RM, Maecker H, Davis MM, Nguyen PK, Wu SM. Cardiovascular complications in patients with COVID-19: Consequences of viral toxicities and host immune response. Current Cardiology Reports. 2020;22:1-9.

[15] Shereen MA, Khan S, Kazmi A, Bashir N, Siddique R. COVID-19 infection: Origin, transmission, and characteristics of human coronaviruses. Journal of Advanced Research. 2020 Mar 16.

[16] Madjid M, Miller CC, Zarubaev VV, Marinich IG, Kiselev OI, Lobzin YV, Filippov AE, Casscells III SW. Influenza epidemics and acute respiratory disease activity are associated with a surge in autopsy-confirmed coronary heart disease death: Results from 8 years of autopsies in 34892 subjects. European Heart Journal. 2007;28(10):1205-10.

[17] Dhainaut JF, Claessens YE, Janes J, Nelson DR. Underlying disorders and their impact on the host response to infection. Clinical Infectious Diseases. 2005;41(Supplement_7):S481-9.

[18] Madjid M, Safavi-Naeini P, Solomon SD, Vardeny O. Potential effects of coronaviruses on the cardiovascular system: A review. JAMA Cardiology. 2020 Mar 27.

[19] Wu Z, McGoogan JM. Characteristics of and important lessons from the coronavirus disease 2019 (COVID-19) outbreak in China: Summary of a report of 72314 cases from the Chinese Center for Disease Control and Prevention. Jama. 2020;323(13):1239-42.

[20] Pal R, Bhansali A. COVID-19, diabetes mellitus and ACE2: The conundrum. diabetes research and clinical practice, 2020;162.

[21] Dimsdale JE. Psychological stress and cardiovascular disease. Journal of the American College of Cardiology. 2008;51(13):1237-46.

[22] Harris ML, Oldmeadow C, Hure A, Luu J, Loxton D, Attia J. Stress increases the risk of type 2 diabetes onset in women: A 12-year longitudinal study using causal modelling. PLoS One. 2017;12(2).

[23] Ross A, Brooks A, Touchton-Leonard K, Wallen G. A different weight loss experience: A qualitative study exploring the behavioral, physical, and psychosocial changes associated with yoga that promote weight loss. Evidence-Based Complementary and Alternative Medicine. 2016;2016.

[24] Shantakumari N, Sequeira S. Effects of a yoga intervention on lipid profiles of diabetes patients with dyslipidemia. Indian Heart Journal. 2013;65(2):127-31.

[25] Hagins M, Selfe T, Innes K. Effectiveness of yoga for hypertension: Systematic review and meta-analysis. Evidence-Based Complementary and Alternative Medicine. 2013;2013.

[26] Parshad O. Role of yoga in stress management. The West Indian Medical Journal. 2004;53(3):191-4.
[27] Lancet T. India under COVID-19 lockdown. Lancet (London, England). 2020;395(10233):1315.

[28] Maji A, Sushma M, Choudhari T. Implication of InterState Movement of Migrant Workers during COVID 19 Lockdown using Modified SEIR Model. arXiv preprint arXiv:2005.04424, 2020.

[29] Bradbury-Jones C, Isham L. The pandemic paradox: The consequences of COVID-19 on domestic violence. Journal of clinical nursing, 2020.

[30] Ranney ML, Griffeth V, Jha AK. Critical supply shortages - the need for ventilators and personal protective equipment during the Covid-19 pandemic. New England Journal of Medicine. 2020;382(18):e41.

[31] Shanafelt T, Ripp J, Trockel M. Understanding and addressing sources of anxiety among health care professionals during the COVID-19 pandemic. Jama, 2020.

[32] Rajkumar RP. COVID-19 and mental health: A review of the existing literature. Asian Journal of Psychiatry. 2020:102066.

[33] Chida Y, Hamer M. Chronic psychosocial factors and acute physiological responses to laboratory-induced stress in healthy populations: A quantitative review of 30 years of investigations. Psychological Bulletin. 2008;134(6):829.

[34] Stein M, Keller SE, Schleifer, Immune system: Relationship to anxiety disorders. Psychiatric Clinics of North America. 1988;11(2):349-60.

[35] Marsland AL, Bachen EA, Cohen S, Rabin B, Manuck SB. Stress, immune reactivity and susceptibility to infectious disease. Physiology \& Behavior. 2002;77(4-5):711-6.

[36] Pang S, Wu H, Wang Q, Cai M, Shi W, Shang J. Chronic Stress Suppresses the Expression of Cutaneous Hypothalamic-Pituitary-Adrenocortical Axis Elements and Melanogenesis. PLoS One. 2014;9(5).

[37] Karasek M. Melatonin, human aging, and age-related diseases. Experimental Gerontology. 2004;39(11-12):1723-9.

[38] Tan DX, Hardeland R. Potential utility of melatonin in deadly infectious diseases related to the overreaction of innate immune response and destructive inflammation: Focus on COVID-19. Melatonin Research. 2020;3(1):12043.

[39] Immunity at risk as lockdown, isolation messes up sleep cycle, in The Times of India. 2020: Ranchi.

[40] Orozco-Solis R, Aguilar-Arnal L. Circadian regulation of immunity through epigenetic mechanisms. Frontiers in Cellular and Infection Microbiology. 2020;10:96.

[41] Gautret P, Lagier JC, Parola P, Meddeb L, Mailhe M, Doudier B, Courjon J, Giordanengo V, Vieira VE, Dupont HT, Honoré S. Hydroxychloroquine and azithromycin as a treatment of COVID-19: Results of an open-label non-randomized clinical trial. International Journal of Antimicrobial Agents. 2020:105949.

[42] Ledford H. Hopes rise for coronavirus drug remdesivir. Nature, 2020.

[43] Cao B, Wang Y, Wen D, Liu W, Wang J, Fan G, Ruan L, Song B, Cai Y, Wei M, Li X. A trial of lopinavir-ritonavir in adults hospitalized with severe Covid-19. New England Journal of Medicine. 2020.

[44] Tillu G, Chaturvedi S, Chopra A, Patwardhan B. Public health approach of Ayurveda and Yoga for COVID-19 prophylaxis. The Journal of Alternative and Complementary Medicine. 2020;26(5):360-4.

[45] Brisbon NM, Lowery GA. Mindfulness and levels of stress: A comparison of beginner and advanced hatha yoga practitioners. Journal of Religion and Health. 2011;50(4): 931-41. 
[46] Naoroibam R, Metri KG, Bhargav H, Nagaratna R, Nagendra HR. Effect of Integrated Yoga (IY) on psychological states and CD4 counts of HIV-1 infected patients: A randomized controlled pilot study. International Journal of Yoga. 2016;9(1):57.

[47] Streeter CC, Gerbarg PL, Saper RB, Ciraulo DA, Brown RP. Effects of yoga on the autonomic nervous system, gammaaminobutyric-acid, and allostasis in epilepsy, depression, and post-traumatic stress disorder. Medical Hypotheses. 2012;78(5):571-9.

[48] Segerstrom SC, Miller GE. Psychological stress and the human immune system: A meta-analytic study of 30 years of inquiry. Psychological Bulletin. 2004;130(4):601.

[49] Mahajan AS. Role of yoga in hormonal homeostasis. International Journal of Clinical and Experimental Physiology. 2014;1(3):173-178.
[50] Bernardi L, Spadacini G, Bellwon J, Hajric R, Roskamm H, Frey AW. Effect of breathing rate on oxygen saturation and exercise performance in chronic heart failure. The Lancet. 1998;351(9112):1308-11.

[51] Shree N, Bhonde RR. Can yoga therapy stimulate stem cell trafficking from bone marrow? Journal of Ayurveda and Integrative Medicine. 2016;7(3):181-4.

[52] Ofei-Dodoo S, Cleland-Leighton A, Nilsen K, Cloward JL, Casey E. Impact of a Mindfulness-based, Workplace Group Yoga Intervention on Burnout, Self-care, and Compassion in Health Care Professionals: A Pilot Study. Journal of Occupational and Environmental Medicine. 2020.

[53] Nagarathna R, Nagendra H, Majumdar V. A perspective on yoga as a preventive strategy for coronavirus disease 2019 . International Journal of Yoga. 2020;13(2):89. 